\title{
Improving the assessment of financial and management reporting elements
}

\author{
Enlik Baisheva ${ }^{1}$ \\ Indira Aubakirova² \\ Camila Gaitova ${ }^{3}$ \\ University of International Business, Kazakhstan \\ 12606689@mail.ru \\ 2indira_aubakirova91@mail.ru \\ 3k.gaitova@gmail.com
}

\begin{abstract}
The purpose of the research is to discuss current issues and to unify financial and managerial accounting as a single unit of accounting and application in practice. In the process of the research, the following methods were used: system approach, observation, comparison, grouping and modeling. The research materials are used in the practical activities of financial and economic services of LLP "Hitten Tobacco Kazakhstan" in particular, a set of methodological techniques for preparing financial statements.

The scientific novelty of the research consists in working out conceptual approaches to the formation of financial statements, practical development of organizational and methodological provisions relating to the reporting organizations. The study obtained the following most important scientific results are submitted for protection: a model for formation of financial and management reporting in the entities acting in a specific industry analyzed the organization; updated classification of elements of information in financial statements in accordance with the developed concept; an algorithm for testing economic operations in accounting for compliance with the concept; an algorithm for managers ' actions to reflect income and expenses in accounting; a method for comparative analysis of parameters of elements of information in financial statements converged to IFRS in accordance with the proposed model.

The theoretical significance of the research is to expand the information boundaries of financial statements. The practical significance is that the developed set of methodological solutions for the preparation of financial statements will ensure their verifiability and comparability and will serve as a basis for the preparation of reports of economic entities.
\end{abstract}


Keywords: financial statements, accrual principle, continuity principle, income, expenses, capital. 


\section{Introduction}

In the modern economy, there is an obvious need to integrate corporate governance methods into a single system that would support the adoption of economically balanced management decisions, increase labor productivity and competitiveness of enterprises. This is a question not only of effective management of the enterprise, but also of its existence in a highly competitive environment, including at the international level.

In conditions of Hyper-competition, instability of the external environment, growing inflation, organizations need to effectively manage the enterprise, which depends on the level of its information support provided by the accounting system. Effective work of a modern organization is impossible without a well-established management accounting system, which is a subsystem of accounting, which within the organization provides the apparatus at all levels of information management used for planning, proper management and control of its activities. As a process, management accounting includes the identification, measurement, collection, analysis, preparation, interpretation, transmission and reception of information necessary for the management apparatus to develop optimal management decisions.

Until recently, management accounting, which was mainly aimed at providing information for operational decisions, is called traditional.

In addition to operational management decisions, a modern enterprise needs to make long-term or strategic management decisions. Recently, their importance has increased dramatically, due to increased competition and the emergence of new information opportunities for data processing. It is the focus on the long-term goals of the company that contributes to more stable benefits that quickly offset short-term advantages.

This leads to the conclusion that new methods of management accounting are needed to serve the needs of the company's management when preparing strategic decisions. In this case, we are talking about a new direction of management accounting, called strategic management accounting, aimed at providing information for strategic decisions. In turn, this leads to the use of analytical methods and completely new relationships between management accounting and other related disciplines: financial accounting, management, marketing, etc. 
The main function of strategic management accounting is to provide conditions for the most objective analysis of the company's performance, as well as to ensure that the wishes of all groups of stakeholders are considered when making strategic management decisions. In other words, strategic management accounting should allow you to determine how effectively the organization works from the point of view of various interest groups.

A well-established system of management accounting and reporting for managers at all levels of management is necessary for a modern organization to work effectively in whatever area of the economy it operates in.

\section{Literature Review}

State of development of the problem. Studies of regulation of accounting, the subject of numerous works of Russian and foreign scientists including Makhmudov and Kerimov (2020).

Theoretical and scientific-methodological work in the study of problems has been widely developed in the economic literature and reflected in the works of such writers of the Republic of Kazakhstan, such as Nurseitov (2015) and Markhaeva (2017).

\section{Methods}

The research methodology is based on General scientific methods of knowledge, principles and criteria of objectivity in their versatility and inconsistency, based on the totality of works of domestic and foreign scientists, statistical indicators that correspond to the truth and General laws of state and socio-political development at the historical stage under study.

\section{Sample}

The information base of the research consists of legislative acts, resolutions and other state program documents of the Republic of Kazakhstan, as well as information contained in official documents, scientific, reference and periodical literature on the topic under study. 
The research information base consists of materials of scientific and research conferences and seminars; statistical information contained in scientific publications.

\section{Findings}

Management accounting was organized in the process of separating accounting from other professional areas. Management accounting is mostly not related to accountants who are engaged in financial and tax accounting, but it also includes taxes, internal control, internal audit, performance measurement, management control, and so on. The motivation to combine persons responsible for financial and managerial accounting, apparently, is due to four factors:

1. The Development of Blockchain technologies threatens the positions of ordinary accountants who are not related to management accounting.

2. Separate financial and management accounting may lead to distortions and affect the quality of management decision-making, because the accountant for management accounting may not have detailed information.

3. Internal and external users of reporting are subject to negotiations with various persons representing only one side of the organization's global accounting.

4. The Financial Manager is not a material responsible person in the organization, is not responsible to the tax and other state authorities, while this responsibility is assigned to the chief accountant, who just controls the financial and tax accounting.

The relationship between financial and management accounting as technologies is complex. On the one hand, management accounting systems provide cost data and inventory estimates that are used to support financial reporting and are subordinate to financial reporting in this sense. There is no doubt that management accountants and financial accountants share a common knowledge base. On the other hand, management accountants were asked to act as internal consultants in organizations, focusing on strategic initiatives and performance assessment/management, rather than on routine costing processes. Management accounting focuses on aspects of managing or implementing management actions, while financial accounting focuses on the investment use of information. Thus, Management accounting is at the same time a profession that supports financial reporting, trying to go beyond this narrow area. 
The financial Manager position involves partnership in making management decisions, developing planning and performance management systems, and providing expertise in financial reporting and control to help management develop and implement the organization's strategy.

An outline of the development of management accounting as a technology of practical activity indicates that management accounting differs from financial accounting in the:

1. Focus on opportunity costs to support management decision-making and encourage different information for different decisions within the same organization.

2. Providing information relevant to a broad group of stakeholders, rather than focusing on information relevant to the shareholder decision-making model.

3. Variation of management accounting practices depending on the organization's strategy, in particular, in the selection of performance indicators to stimulate the implementation of the strategy and build information specific to decision-making by internal users. In figure 1, we see that the basis for building financial and management accounting is unified, therefore, it allows for the unification of accounting.

Management accounting is information provided to internal users for the purpose of making management decisions, developing strategies for further business development, and building strategic plans. If financial accounting is considered as a rule in short-term periods, projects of management tools are developed as a rule on a long-term basis, i.e. for a period of more than 1 year (Ivashkevich, 2016). These include budgets (each company has a different approach, and a tight / flexible budget). Management accounting is based on financial accounting, but it has no time limits, forms, and is not required to maintain, unlike financial and tax accounting (Volkov, 2016). With the help of management accounting, users can make decisions, assess the level of expenditures of certain departments and assess the return on investment, understand the volumes at which the company does not risk being in a loss (break-even point). Management accounting is considered at a more global level, so the data may differ from financial accounting, because management accounting may not consider certain costs that do not reach the level of materiality of the organization (Nurseytov, 2015). 
Financial accounting is a system for recording all business operations of an organization. Financial accounting is the basis for financial reporting that is used by external users, for management reporting that is used by internal users, and for tax and statistical reporting that is used by the state. High-quality financial accounting is an important component of any organization, because it is presented to a large number of users for decision-making, and may also include risks that may arise by reporting to the state (tax/statistical accounting). Financial accounting differs from management accounting in that management accounting is not maintained in all organizations, is not mandatory, is not regulated by legal acts, and does not have approved reporting forms and deadlines for its submission (Markhaeva, 2017).

Since the beginning of 2019, the issue of implementing Blockchain and EDO technologies has been actively discussed. These technologies involve the introduction of Bots, as an alternative to accountants for processing primary documentation (bookkeepers), accountants for reflecting operations on the economic activities of organizations and other operations directly related to the formation of transactions for financial statements. In our opinion these technologies are a great innovation because:

1. Get rid of the routine processes of entering transactions.

2. The introduction of EDO will reduce the use of paper (Eco-friendly).

3. EDI involves changes in tax legislation, in terms of the Statute of limitations on the storage of primary documentation (on paper).

4. As the blockchain and EDO are an innovation and development in technology.

The above points are positive, but there is also a negative side of these innovations, such as "staff reduction". In summary, we would like to note the importance of integrating management and financial accounting in order to save jobs for accountants, which will be replaced by bots in the near future (Beyer et al., 2010).

The call for a unified accounting system for both management decision-making and stakeholder reporting has deep roots. It is based on three considerations. 


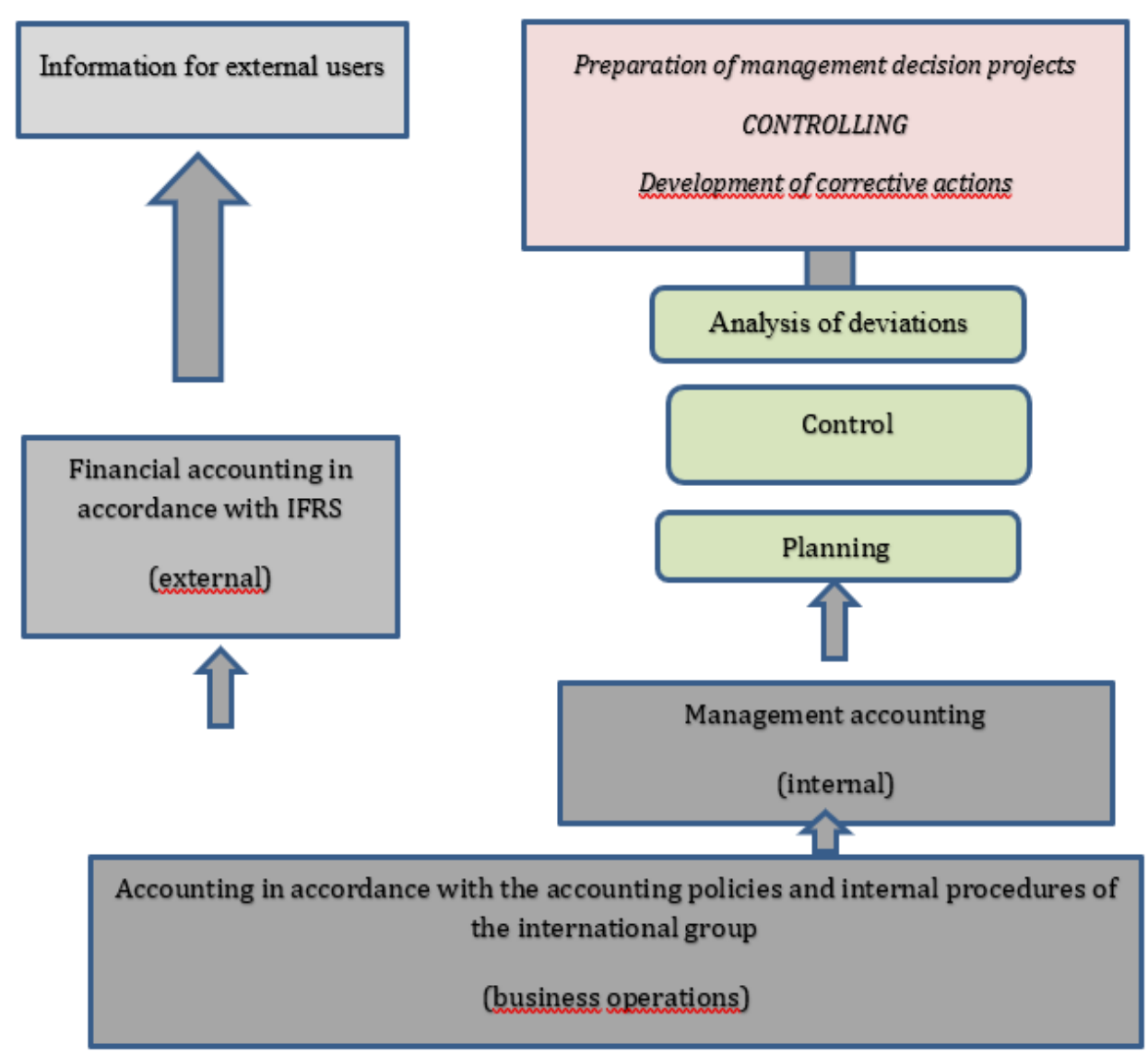

Figure 1. Basis, purpose, and users of financial and management reporting. Note: developed by the author.

First, in an equity-oriented economy, it is argued that managers should always act in the interests of shareholders, i.e. their decisions should be aimed at maximizing shareholder value. Financial reporting provides the means by which shareholders control management, and is often used to build compensation systems designed to align the interests of management with the interests of shareholders (Medianki, Sargiacomo and Walker, 2015). But more than that, it is argued that shareholders should be able to see the information on which managers make their decisions in order to distinguish between good / bad results and good / bad decisions, i.e. to separate skill from luck (Granlund and Malmi, 2002). This suggests that the information system used by management should be a more detailed and up-to-date version of the information provided to shareholders. This logic also challenges developers of financial reporting standards to reject current standards and adopt those that have proven their value.

Thus, if financial statements are based on information that determines shareholder value, and management reporting allows you to evaluate performance based on it, why do managers use a different set of information when making decisions? 
A related trend in both management and financial accounting is risk orientation. The concept of risk draws attention to possible future results and contingencies for the organization, as well as to whether the organization can withstand shocks (business resilience), respond constructively to challenges (contingency planning), and innovate to meet new challenges (innovativeness). Financial statements with their traditional backward perspective were not sufficient to provide an insight into this aspect of corporate activity. This argument in favor of integration assumes that the merger of management accounting and financial accounting and is an innovation (Hein, 2014).

Second, the development of information technologies that allow real-time data collection and reporting eliminates the need to keep records in separate systems for making management decisions. Norton and Kaplan (2010, p.61-64) suggested that financial reports were "too aggregated, too distorted, and too late" to be useful for managerial decision-making. This criticism, in particular, presupposes the conditions under which financial statements can be used for managerial decision - making, i.e. if it was available in a disaggregated form, made theoretically reasonable distinctions between cost categories, and used theoretically acceptable allocation methods (including not allocating true shared costs), and was available in real time. Hopper et al. (1992) report a pilot study in which they examined whether financial accounting systems dominate management accounting systems. They found that among their small sample, both financial accounting and management accounting rely on the same database, but process and format information in different ways. Although this implies a level of integration around "primitive" credentials, both systems can maintain their independence. However, if the underlying "primitive" system is based on an ontology of financial accounting (i.e. limited to transactional, verifiable information), it remains unclear whether the potential of management accounting information can be realized. The existence of" popular accounting systems " along with formal accounting systems of organizations suggests that this form of integration may not fully meet the information needs of managers.

Finally, the transition to market-based information in accordance with IFRS weakens the requirement that financial statements be based on transaction data and opens the possibility that the "opportunity cost" information recommended for management decisions may correspond to the information provided in the financial statements. 
However, as Kaplan notes (Kaplan and Norton, 2010 p.34-39), the "fair value" provisions of IFRS are among the most controversial aspects of global standards and are an area where there will be significant internal differences in application.

Transition of management accounting systems in Germany from Autonomous to integrated management accounting/financial accounting systems to explore the potential benefits of integration. They do not find a direct technical benefit from the change, but report a positive relationship between the change and the effectiveness of the control function within the firm, based on creating a single "language" for discussing both investor and management issues. Although this has not been verified, it can be assumed that a similar benefit would be found if the financial reporting system switched to a management accounting framework. However, integration usually refers to the abandonment of a separate management accounting system in favor of a compliancebased financial accounting system.

Management accounting as a separate field and body of knowledge is a relatively recent addition and differentiation of the accounting profession. This is the creation of mostly Anglo-Saxon countries, and individual management accounting associations outside this context are less common. The existence of separate associations of management and financial accountants creates competition and conflict between professional associations. The trend is to resolve these issues by consolidating accounting lines.

Management accounting as a practice technology focuses on the decision-making needs of managers and on supporting managers in implementing strategies and managing a diverse group of stakeholders. While there are good reasons for maintaining the distinction between management and financial accounting, the continuing trend of separation of professional associations dealing with financial reporting and auditing means that these calls should be taken seriously. All this raises the question: is there an independent future for management and financial accounting as technologies and directions?

To the extent that management accounting has become a practical technology that goes beyond investment-oriented information and is aimed at predicting changes in the information needs of various stakeholders, incentives remain for the development of this integration technology. 
There are good reasons for maintaining the distinction between management and financial accounting, and the continuing trend of separating professional associations dealing with financial reporting and auditing means that these calls should be taken seriously. All this raises the question: is there an independent future for management and financial accounting as technologies and directions?

To the extent that management accounting has become a practical technology that goes beyond investment-oriented information and is aimed at predicting changes in the information needs of various stakeholders, incentives remain for the development of this integration technology. Improving the assessment of the effectiveness of the management accounting system should help to solve problems in the functioning of the management accounting system, which, in turn, hinder the effectiveness of the organization as a whole. Therefore, it is important to list the main problem points, the elimination of which is necessary to focus the program on improving and developing the evaluation of the effectiveness of the management accounting system, which in turn is the subject of internal audit of the management accounting system in the organization.

Recommendations for improving the management reporting system and optimizing the information base that supports it are presented below.

The following areas of improvement of the management accounting and reporting system were selected as priorities:

1. Improving the structure, hierarchy, content and presentation of management reports.

2. Development of the financial planning and budgeting system.

3. Development of the company's development strategy with subsequent linking of short -, medium-and long-term planning horizons.

4. Improving the cost accounting system.

Figure 2 shows current accounting. The study showed that this system is not effective, labor-intensive and can distort the results of economic activity. 
Shown in Figure 3 accounting system, will allow the organization to reduce a lot of routine processes, optimize the operating part, reduce costs in terms of remuneration and automate accounting in General.

As a result of the research, we can identify recommended ways to improve the management accounting and reporting system in the organization.

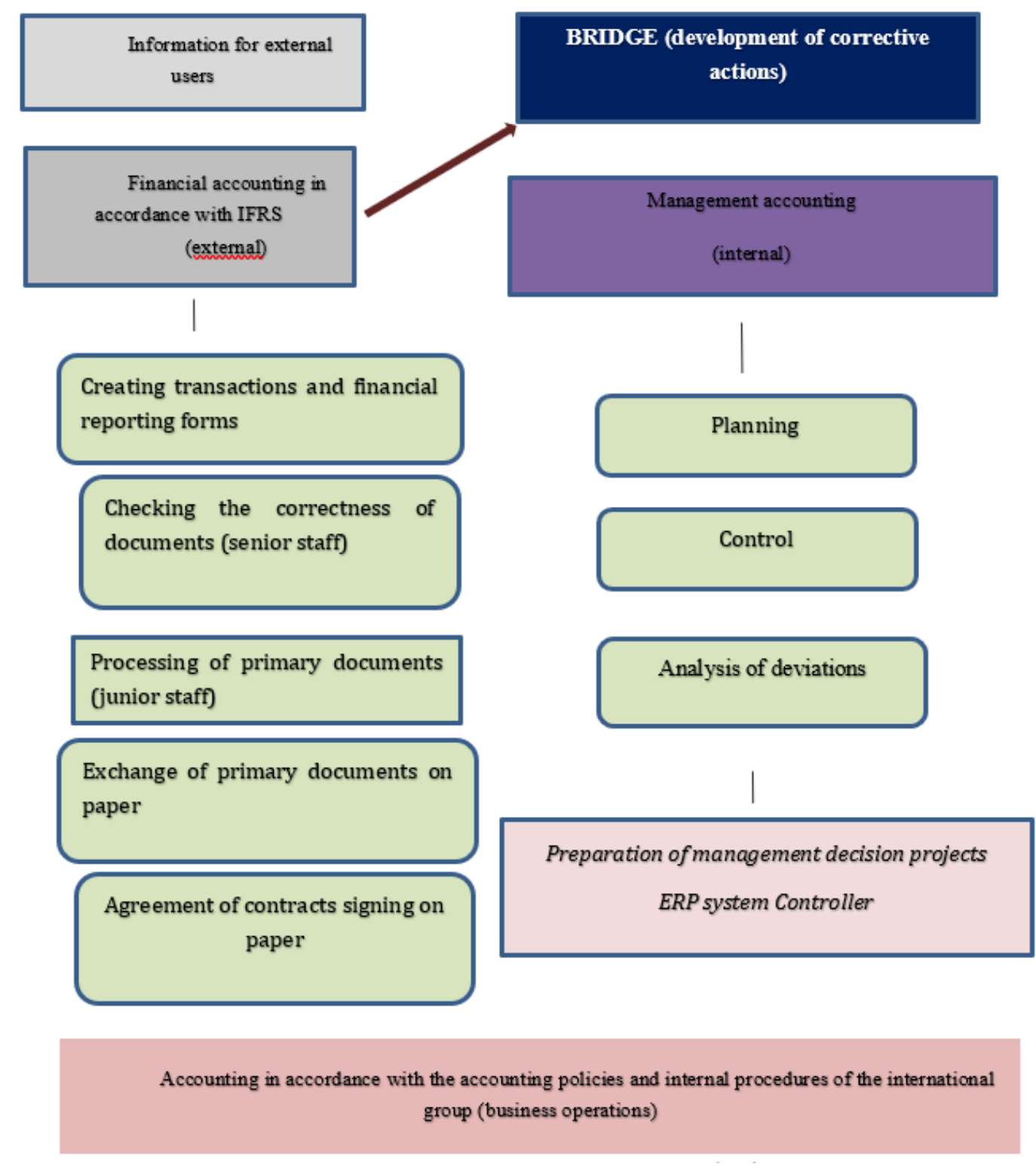

Figure 2. Accounting Scheme of LLP Hitten Tobacco Kazakhstan. Note: developed by the author based on management report.

- Designing an optimal hierarchy of reports and adapting them to the needs of managers at various levels. 


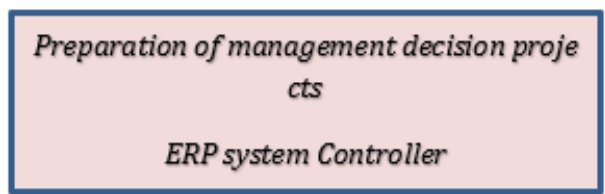

Information for external users

Management accounting on the basis of financial accounting according to IFRS

Control functions of the financial and management accounting Department

Introduction of electronic document management
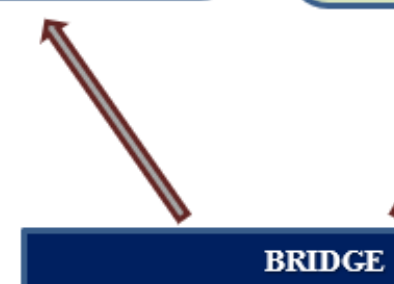

(upgrated 1C)

Development and adoption of Blockchain technology, in the form of bots that process electronic documents and write transactions

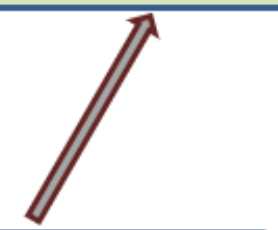
C)

Accounting in accordance with the accounting policies and internal procedures of the international group (business operations)

Figure 3. Unified financial and management accounting. Note: compiled by the author as a result of research.

- Development of a system of long - term (5-10 years) and medium - term (3-5 years) planning based on the assessment of the company's competitiveness in the domestic and global markets.

- Linking long-term, medium-term, and current planning.

- Optimization of the budgeting system.

- Improvement of the cost accounting system and the regulatory framework for calculating their planned level.

As part of the first direction-improving the management reporting system, defining the hierarchy of reports and adapting them to the needs of managers at various levels - the most significant activities are the following:

- Analysis of the current management reporting system, its composition, structure and functions, as well as organizational and technical aspects of its functioning. 
- Assessment of the level of automation of information flows and decision-making processes and, if necessary, bringing them in line with the requirements of the management accounting reporting system.

The role of management accounting in ensuring the correct use of enterprise resources and determining the scope of responsibility of each Manager is clearly understood. But determining the expected income from a particular economic event, making a forecast of the profitability of new products, forecasting the financial position of the company in the future and financial assessment of options for the development of the enterprise, as the main tasks of management accounting, are not widely used. Also, we are not talking about the use of elements of strategic management accounting: providing employees with essential information; using financial and non-financial indicators in determining performance, and others. While the introduction of traditional management accounting in Kazakhstan is only taking the first steps, Western scientists are already talking about the need for radical changes in the structure of strategic management accounting.

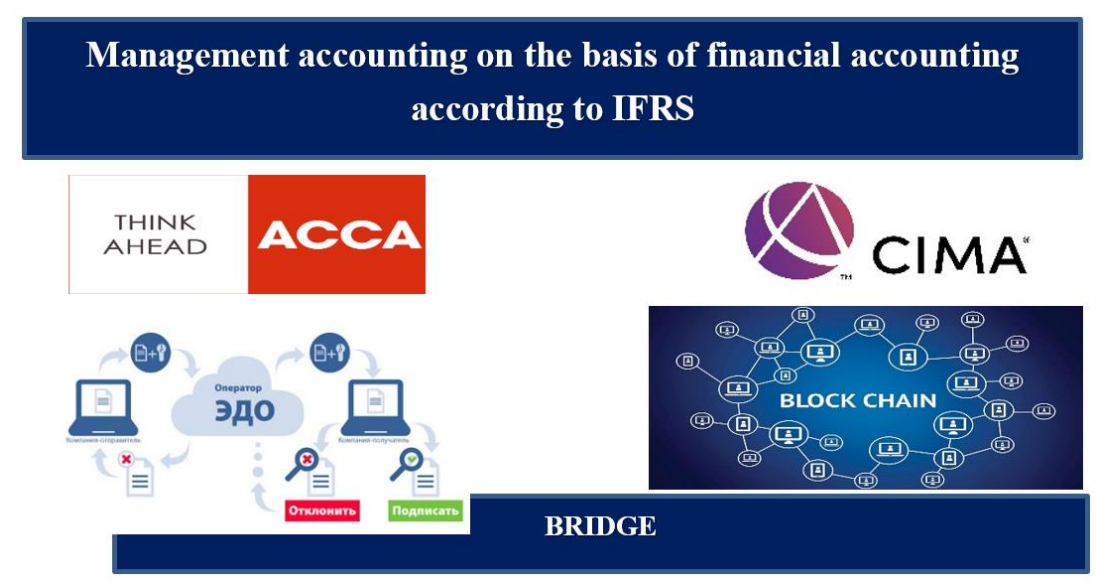

Figure 4. Unified financial and management accounting. Note: developed by the author.

Based on a set of primary indicators, it is possible to build a number of small information systems, the use of which is aimed at solving local management problems. Each system with its own indicators and their information carriers (documents) ensures the implementation of specific management functions. This is an objective prerequisite for the appearance of an independent type of accounting - financial and managerial. Systematization of indicators in analytical and synthetic accounting is always aimed at the final result - the formation of necessary information for specific users. This, in turn, 
makes it necessary to interpret analytical data and indicators of financial statements taking into account the set goals. The purpose of the concept of accounting unification is to create a system of accounting and reporting based on the adoption and use of rules and regulations that do not contradict the legal framework and comply with the provisions of international standards. The development of the management accounting system, accompanied by the improvement of the organizational structure, could provide the necessary information support for making responsible management decisions at a lower management level and facilitate the delegation of appropriate responsibility from the top to the middle level of management.

\section{Conclusions}

In the course of the research, the main principles for the development and improvement of strategic management accounting were formulated. The organization and improvement of strategic management accounting is an internal matter of the organization itself. The main and indisputable argument for improving management accounting is the economic environment. The development of market relations forces managers of organizations to make management decisions on a variety of issues of the organization's activities and bear the risk and responsibility for the justification of each of them. A scheme for improving strategic management accounting is proposed. The proposed scheme for improving strategic management accounting is a set of interrelated and mutually dependent components that form a single, integral, continuous process of forming an effective organization of strategic management accounting in the enterprise. We would like to expand the scope of management audit, extending it to the accounting and analytical subsystem, personnel management and other elements of the organization. This approach is associated with the need to fully cover all elements of the organization by management audit methods, since the loss of one of their elements will not allow forming a complete picture of the financial situation of the organization and will make it difficult to make effective decisions. Currently, some of the listed objects of management audit have developed original methods, including the method of management audit of personnel.

Recognizing the novelty and effectiveness of these methods, it is necessary to point out the fragmentary nature of research. This indicates the formation of management audit, the search for optimal ways of its development. 
The effective functioning of an organization is determined by optimizing its structure and activities of segments, which in turn requires improving the accounting and analytical subsystem, internal control system, etc.

In this context, a special place is given to improving management audit. The specifics of management audit as a relatively new branch of economic knowledge and its versatility require the use of non-traditional tools. Among them should include diagnosis and decomposition of the system.

Implementation of the goals and objectives of management audit, its improvement through the use of diagnostics allow for a system-problem approach and logical-critical analysis of management subsystems (sales, supply, pricing, etc.). Identification of features and trends in the development of each subsystem determines the definition of global problems in the development of the organization as a whole and the construction of a clear "financial picture" of the economic entity. Diagnostics can be used in the context of checking the effectiveness of sections of the accounting and analytical subsystem and the internal control system.

It is advisable to use system decomposition in parallel with its diagnostics, which will provide a comprehensive approach to solving management audit tasks. Developing market relations call for the formation of a system for managing capacious, flexible, reliable financial information, the source of which is financial accounting. The relationship between financial accounting and management plays a special role at this stage of accounting development. To show this relationship, the value of accounting information for the functioning of the system as a whole is determined.

Summarizing the above, we can characterize the diagnostics and decomposition of the management system in the framework of management and financial accounting as powerful and effective tools for research of economic and other problems of the organization. Comparative analysis of management accounting and financial have shown that their major differences lie in such features as customer data (managerial accounting designed to provide information to the company's management and financial, mainly for external users), focus (purpose management accounting support for the process of managerial decision-making, goal financial and the preparation of financial statements), freedom of choice of methods (management accounting can be carried out almost any methods, financial - strictly regulated by regulatory documents), etc. 
Today, there are many tools for management accounting - various types of budgets, reporting and analytical forms, methods for allocating overhead costs, etc. While outside the scope of the studies remains a fundamentally important question, how to shape the management accounting system of a specific enterprise to provide the company's management the necessary information with the specific activities of the control object. In other words, how to adapt a variety of existing tools to the needs of a particular enterprise in order to use them for making management decisions. The lack of developments in this area leads to the fact that management accounting at the enterprise is either not conducted at all, or it is conducted formally, i.e. reports, budgets, and other documents are compiled, but their actual use in making management decisions is very limited, which dramatically reduces the effectiveness of the management process.

In connection with the above, there is a need to create a technology for the formation and implementation of a management accounting system in a specific enterprise. The formation of the management accounting system at the enterprise is inextricably linked and is a consequence of the General concept of enterprise management. As a basis for such a concept, a project approach can be proposed, in which the activity of the enterprise is considered as the implementation of a certain set of projects. Moreover, this approach can be applied not only in purely project companies, but also in almost any enterprise. In this case, the concept of enterprise management is reduced to optimizing project management as a complete system and optimizing the management of the implementation of an individual project, and the goal of management is to form a balanced portfolio of projects and optimize the implementation of individual projects. The proposed synchronization of financial and management accounting systems is aimed at optimizing the process of automating report generation. The transition to a single unified accounting policy will significantly increase the prospects and reduce the complexity of automating the process of forming two types of reporting formats. The development and application of innovative information platforms where accounting and analytical information can be generated by various segments (including geographically remote ones) via the Internet and analyzed online - all this significantly improves the prospects for effective and high-quality formation of automated management and reporting under IFRS.

It is important to note that the integrated system helps to optimize the unification of organizational and methodological simplification of structuring and integration of 
financial, management and other reporting by dissolving the interchangeable departments of IFRS and management accounting, while removing possible conflict situations between the centers of responsibility. The development of a unified methodological platform intensifies the process of financial integration in the group of companies and minimizes the costs of forming consolidated management reports, which is due to the fact that there is no motivation to identify all accounting differences and make transformational adjustments.

Summarizing the above, it can be noted that in order to ensure at the present stage that the control bodies of the enterprise can carry out inspections within the framework of the implementation of the management accounting system, it is necessary to focus on solving the most important tasks of forming an appropriate methodological base that establishes the main procedures and algorithms for carrying out control measures to build a management and financial accounting system.

\section{References}

Makhmudov, A.R. and Kerimov, V.E. (2020). Development of management accounting for investments in the creation of innovative products in agricultural organizations. Moscow: Publishing House Dashkov i $\mathrm{K}^{\circ}, 160 \mathrm{p}$.

Ivashkevich, V.B. (2016). Accounting management: Textbook for university students enrolled in the specialty 060500 Accounting, Analysis and Audit. Moscow: Yurist, $618 \mathrm{p}$.

Volkov, D.L. (2016). Financial accounting: theory, practice, organization reporting: Textbook. Allowance. - SPb: Publ. house of St. Petersburg. Gos. University, 640 p.

Nurseytov, E.O. (2015). Accounting in organizations: textbook. Almaty: Bilim, 472 p.

Markhaeva, B.A. (2017) Management Accounting: Study Guide. Almaty: IP Balausa, 208 p.

Beyer, A. Cohen, D. A. Lees, T.Z. and Walter, B.R. (2010). Financial Reporting Environment: Overview of modern literature. Journal of Accounting and Economics, 50 (2), 343.

Medianki, S., Sargiacomo, M. and Walker, P.S. (2015). Consolidation and double closure in the Italian accounting profession, 1861-1906. European Accounting Review, 24 (1), 197. 
Granlund, M. and Malmi, T. (2002). The moderate impact of ERPS on management accounting: lag or permanent result ? Management Accounting Research, 13 (3), 321.

Hein, S. Y. (2014). Hybridized professional groups and institutional work: COSO and the growth of corporate risk management. Accounting, organizations and society, 39 (5), 330.

Kaplan, R. And Norton, D. (2010). Strategic Maps. Transformation of intangible assets into tangible results. Moscow: Olymp-Business, 512p. 